\title{
EL RETO DE HUMANIZAR, REFLEXIONES SOBRE LA URGENCIA DE SER PERSONA
}

\author{
Patricia Ibargüengoitia y Rentería* \\ pibarguengoitia@yahoo.com.mx
}

\section{Eduardo Garza Cuellar \\ Trillas, 2008}

Garza Cuellar nos ofrece una serie de reflexiones dividida en tres partes, cada una de ellas compuesta de diferentes artículos que pueden ser leídos de manera independiente, siempre incitándonos a darnos cuenta de nuestra situación social, carente de amor y de vivencias trascendentales, significativas. Es necesario el descanso como remedio para la tristeza y la desesperanza que se vive en la actualidad. Tomás de Aquino recomienda para ello las lágrimas, un baño relajante y el sueño. Casi nadie lo sabe, o casi nadie lo recuerda, para el caso resulta lo mismo. Conocer, aprender, "platicar" como decimos en México, darnos al Otro, observar, a fin de crecer y desarrollarnos, es la propuesta de esta obra.

Vivir plenamente, buscar a Dios, buscar al Otro, valorar al mundo en que vivimos con sus aberraciones y contradicciones, a fin de desarrollar nuestra creatividad para poner en movimiento y echar a andar en sentido contrario de la destrucción a la que nos conducimos. Tomar en cuenta el desarrollo del espíritu del hombre para construir y crecer. Se trata del mundo, de la naturaleza, del conocimiento, de la ciencia y la tecnología al servicio del hombre y no al revés.

El autor clasifica en colores las tres partes de su libro. La primera son los Textos azules: para darnos cuenta. Es triste, de ahí el color, darnos cuenta de la realidad que nos aqueja. La siguen los Textos amarillos: dedicados al movimiento y a la capacidad de crearlo. Ya iluminados con la luz de la verdad, del análisis de la realidad —es el color amarillo- se vuelve imprescindible tomar acción, ser sugerentes en nuestro ámbito.

Solucionar, darnos al Otro, colaborar con respeto y generosidad en este mundo que tanto nos necesita, como si los demás fueran superiores a

nosotros mismos. Y la parte de los Textos rojos: sobre el sentido, nos recuerda el color de la sangre que circula, la que es vida y le da sentido sólo si la aprovechamos para parar al mundo y girar hacia donde sea necesario a fin de construir con él y de él una morada digna para el hombre creado por Dios y salvado por Él.

Hedonismo, pesimismo, desolación, aburrimiento, búsqueda de di- versión y relajo, características de nuestro tiempo posmoderno que Eduardo Garza analiza con claridad y estilo directos. Espléndida en la presentación de casos e ideas muy sugerentes para una formación integral, que toma en cuenta la dualidad de la 
persona humana: cuerpo y alma. Desarrollo del espíritu a través de la relación personal con nuestro Creador, pues estamos hechos a Su imagen y semejanza y debido a ello somos singulares e irrepetibles. Con nuestra propia manera de darnos al Otro y de aprender, con nuestros talentos y facultades desarrolladas con el fortalecimiento de la voluntad y de la inteligencia en el ejercicio de la libertad. Reconociendo nuestra naturaleza de ser social, de crecer en el Otro y para el otro. Sobre todo en este México nuestro pleno de miserias e ignorancia.

La obra resulta oportuna en un momento en el cual se habla de valores y de ética, después de muchos años de haber desterrado de los planes de estudio la educación cívica y ética en educación básica, y no hablemos de la educación media superior y superior. Cuántos años tenemos los profesores de estos niveles con la discusión con nuestros alumnos de que una cosa es la conducta y otra, muy diferente es el conocimiento de las ciencias y, a veces, sólo a veces, del arte. Sabemos de sobra que el aprendizaje y el desarrollo de la cultura, ésa que cultiva y hace crecer a la persona humana, no es posible en una atmósfera de descalificación hacia el Otro, de egoísmos y protagonismos exagerados o absurdos, de ausencia total del respeto al Otro y a las instituciones, a las autoridades, al mobiliario, a quienes mantienes y cuidan de la presentación y conservación de las ¿qué? y conservación de las instalaciones, por supuesto a profesores y compañeros.

Libertad, justicia, honestidad y respeto son ingredientes insustituibles para crecer en el aula, en la casa, en la calle, en los establecimientos, en la iglesia, es la sugerencia de nuestro autor.

El nivel de bachillerato y el superior, y aún en posgrados, en los que se podría utilizar el texto de Garza, sobre todo su último apartado De místicos y creativos; en él nos comparte algunas experiencias que invitan a reflexionar sobre la realidad de una sociedad sufriente, con crisis de todo tipo: individual, grupal, familiar, económica, intelectual, económica, religiosa; en lugar de anunciar en el currículum personal o empresarial la "cualidad" del liderazgo en algún ámbito, sería deseable comunicar con honestidad y compromiso las virtudes que se practican y se viven en el ejercicio de un trabajo o profesión determinada. No es posible para nadie que quiera vivir de su quehacer para otros, no poseer un espíritu de servicio. Si el más grande sólo vino a eso, a servirnos a todos aquellos que le queramos reconocer y aceptar - porque Él nos da libertad, inclusive para eso- ¿por qué no nosotros también? El sólo poseer los conocimientos técnicos y operativos, no es suficiente, pues de nada sirven si no se tiene la actitud diligente de la prudencia, la fortaleza, el dominio propio, la eficacia y la justicia en la interacción social y transacciones comerciales, aún hablando del mundo con todo y su inevitable globalización. El capitalismo actual, el libre comercio, los negocios internacionales, la economía neoliberal y en general sus con- secuencias en el mundo posmoderno, no habrían llegado al estado actual de explotación, de desempleo, de pobreza, de crimen organizado, si la sociedad tuviera idea de la práctica de la ética como el estudio del acto humano bueno, congruente con su fin último, es decir, la felicidad. 
Sólo así se puede hablar del respeto a la dignidad del hombre y a los derechos humanos fundamentales que tienen su origen en el derecho natural.

¿Podríamos analizar aunque sea una partecita de esta obra en cada una de las asignaturas a partir del bachillerato o en carreras técnicas y hasta los niveles más superiores?

Eduardo Garza Cuellar cita a expertos en el tema de la dignidad de la persona humana como son Víctor Frankl, Carl Rogers, Ortega y Gasset, Gaos, Adela Cortina, Thomas Merto, Javier Sicilia y otros, así como sus biografiados: la señora Armida y Teresa de Calcuta, e inclusive algunos de sus artículos se refieren casi exclusivamente a sus obras. Resulta profundo y agudo en sus observaciones y en la conexión que logra en su lectura con su propio conocimiento y experiencia profesional y con su historia de vida personal. Me parece importante que al final de la obra se nos proporcionaran las fichas completas de los autores citados en el mismo. 